\title{
A simple and low-cost technique for Closed Incision Negative-Pressure Therapy
}

\author{
Dominik A. Walczak, Michał Wojtyniak, Piotr W. Trzeciak, Dariusz Pawełczak, Zbigniew Pasieka
}

\section{TOOLS AND TECHNIQUES}

\begin{abstract}
Surgical site infection (SSI) makes patient care more expensive by prolonging antibiotic usage and hospital stay. Negative pressure wound therapy (NPWT) has been recently reported as a preventive strategy to avoid SSI. We present a simple and low-cost vacuum dressing that may improve surgical wound healing and prevent high-risk wounds from complications.
\end{abstract}

Keywords-Negative pressure wound therapy, Closed Incision Negative-Pressure Therapy, surgical site infection

\section{INTRODUCTION}

$\mathbf{T}$ HE Negative Pressure Wound Therapy (NPWT) is now an accepted method of treatment for chronic wounds or skin grafts. However, an emerging body of literature describes a novel application of NPWT to surgical incisions healing by primary intention. It has been suggested that applying NPWT to a closed surgical incision (Closed Incision NPWT CiNPWT) may hasten the healing of incision and decrease the incidence of wound healing complications, such as infection or dehiscence ${ }^{1 / 2}$ However, these systems are quite expensive, so their usage may be limited in developing countries. This paper presents a simple and low-cost vacuum dressing that may become an alternative to existing commercial products.

The aim of this work is to present how nutrition and nutritional state influences wound healing processes. The patient in whom the appropriate nutritional management was not implemented, in spite of a very intense surgical treatment, with numerous reoperations developed extreme cachexia with the arrest of wound healing.

\section{EQUIPMENT NECESSARY FOR THE DRESSING APPLICATION}

Figure 11 illustrates the basic equipment required for the dressing:

- gauze

- drape (polyurethane adhesive film)

- $50 \mathrm{ml}$ syringe

- 18-22 G needle.

Manuscript received 10.08.2016; revised 20.12.2016. This work did not receive any financial support. Authors declare no conflict of interest.

Author affiliations: Department of General Surgery, John Paul II Memorial Hospital, Belchatow, Poland, (DAW,MW,PWT); Department of Experimental Surgery, Medical University of Lodz, Poland, (DAW,DP,ZP)

*Correspondence to: Dominik Walczak, M.D., Ph.D. email: drdominikwalczak@gmail.com

\section{DRESSING APPLICATION TECHNIQUES}

The dressing is applied at the end of the surgical procedure to the anesthetized patient.

- Dry the peri-wound skin.

- Fold the gauze to make appropriate shapes to fit the size of the wound. (Fig 1B)

- Size and trim the drape to cover the gauze with an additional 2-3 cm border

- Apply the drape over the gauze, including about 2-3 cm of surrounding skin. (Fig 1C)

- Pass the needle on a syringe percutaneously from outside the dressing into the gauze. (Fig 1D)

- Evacuate the air to create negative pressure. (Fig 1D, E) The vacuum dressing is left in place for 48-72 hours. The exudate from the wound is collected in the gauze.

\section{DISCUSSION}

This technique was described for the first time by Oliver Muensterer and Richard Keijzer, $\stackrel{3}{3}$ who used a similar vacuum dressing after single incision pediatric laparoscopic appendectomy. The gauze $(5 \times 5 \mathrm{~cm})$ used in their study was folded two times and covered with a biooclusive dressing. The air was evacuated with $22-\mathrm{G}$ needle on a $10 \mathrm{ml}$ syringe. ${ }^{3}$ To adapt the technique for the larger wounds treated in the present study, a larger size of gauze was used $(7.5 \times 7.5 \mathrm{~cm})$, which was folded only once. As the capacity of the dressing was more than twice that used by Muensterer and Keijzer, a $50 \mathrm{ml}$ syringe was needed to create similar negative pressure.

To evaluate the degree of negative pressure produced by their self-made vacuum dressing, Muensterer and Keijzer applied a dressing and measured the negative pressure by a liquid column. Over five runs, the negative pressure ranged from -34 $\mathrm{mm} \mathrm{Hg}$ to $-44 \mathrm{~mm} \mathrm{Hg}$. This level of negative pressure is about half that produced by commercially available pump-activated vacuum dressings $!^{3}$ However, studies have shown that pressure as low as $-40 \mathrm{mmHg}$ has positive medical effects ${ }^{4}$ Moreover, proportionally much more air may have been removed using the $50 \mathrm{ml}$ syringe, resulting in even greater negative pressure.

The previous study by Muenster and Keijzer demonstrates that a simple, low-cost vacuum dressing has the potential for reducing the wound infection rate in single incision pediatric laparoscopic appendectomy ${ }^{3}$ With our modification, this technique may be useful for other indications where overall wound infection rate is high, such as open appendectomy or ileostomy 

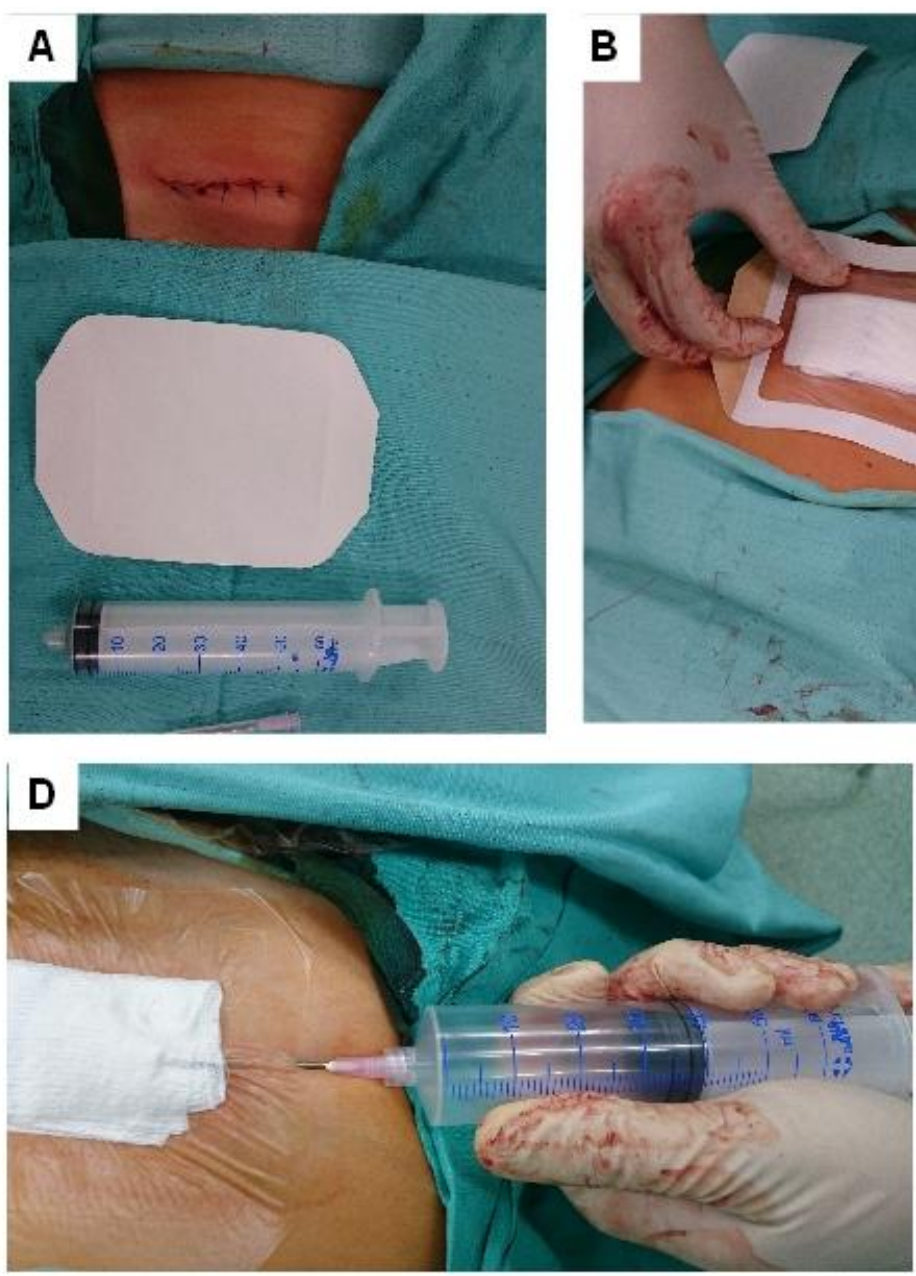
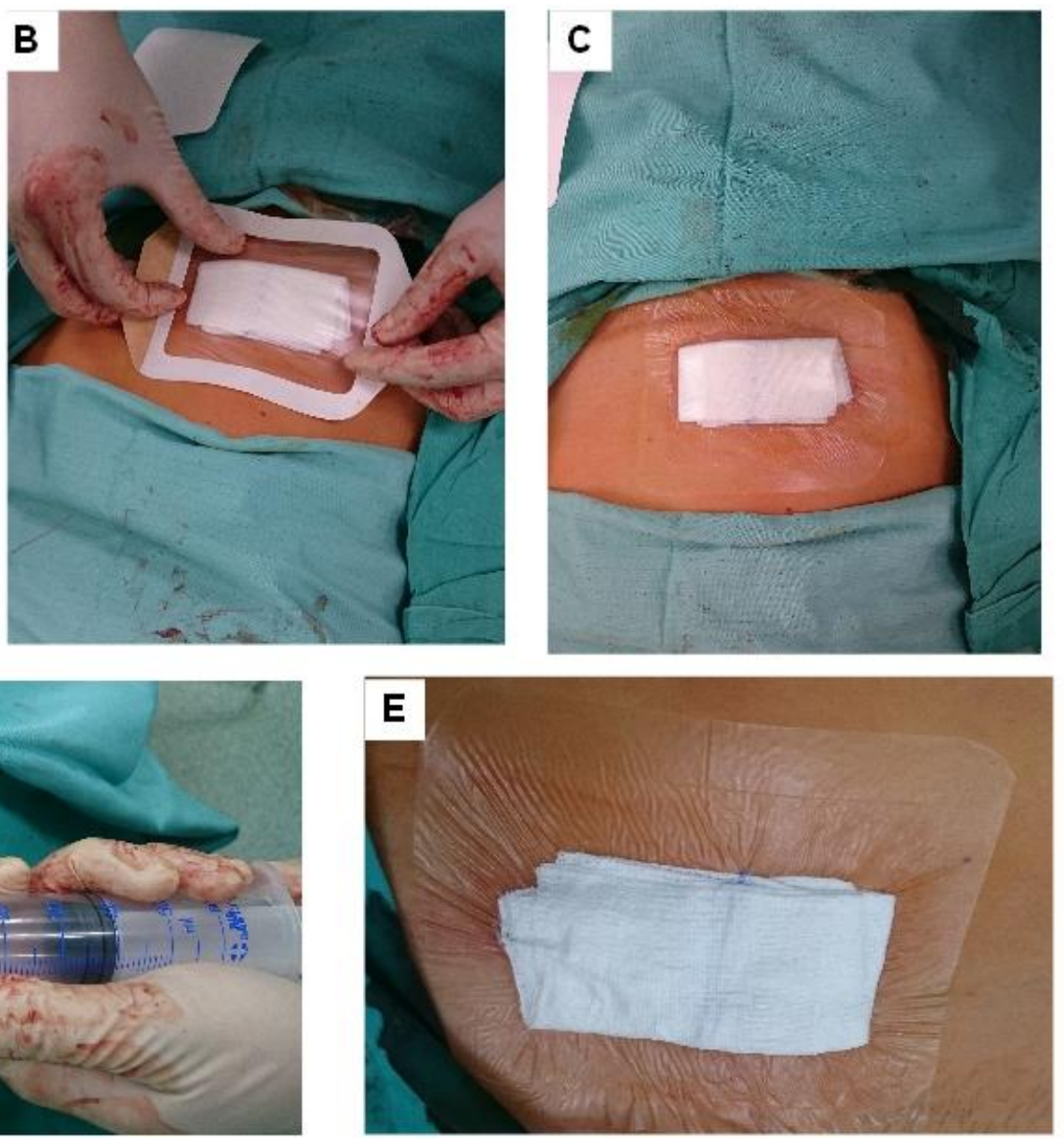

Figure 1. Applying the vacuum dressing. A) wound after open appendectomy and equipment necessary for dressing application; B,C) the gauze is folded, placed onto the wound, and covered with a drape. D,E) A $18-\mathrm{G}$ needle on a $50 \mathrm{~mL}$ syringe is passed subcutaneously from outside the dressing into the gauze and the air around the gauze is evacuated.

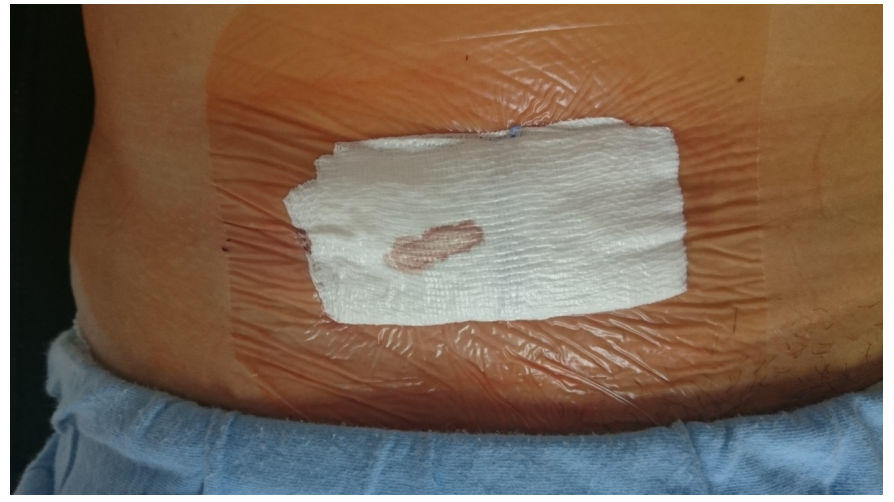

Figure 2. The vacuum dressing after two days

reversal, and not only laparoscopic procedures. The dressing described in the study is able to cover closed surgical wounds that do not exceed $7.5 \mathrm{~cm}$; while much larger wounds could also, hypothetically, be covered, more than one subcutaneous injection should be performed to evacuate the excess air and generate adequate negative pressure.

\section{REFERENCES}

[1] J. P. Stannard, A. Gabriel, and B. Lehner, "Use of negative pressure wound therapy over clean, closed surgical incisions," International Wound Journal, vol. 9, pp. 32-39, jun 2012. [Online]. Available: https://doi.org/10.1111\%2Fj.1742-481x.2012.01017.x

[2] M. J. Ingargiola, L. N. Daniali, and E. S. Lee, "Does the application of incisional negative pressure therapy to high-risk wounds prevent surgical site complications? a systematic review," Eplasty, vol. 13, p. e49, 2013.

[3] O. J. Muensterer and R. Keijzer, "A simple vacuum dressing reduces the wound infection rate of single-incision pediatric endosurgical appendectomy," JSLS : Journal of the Society of Laparoendoscopic Surgeons, vol. 15, no. 2, pp. 147-150, 2011. [Online]. Available: https://doi.org/10.4293\%2F108680811x13071180406592

[4] H. Birke-Sorensen, M. Malmsjo, P. Rome, D. Hudson, E. Krug, L. Berg, A. Bruhin, C. Caravaggi, M. Chariker, M. Depoorter, C. Dowsett, R. Dunn, F. Duteille, F. Ferreira, J. F. Martínez, G. Grudzien, S. Ichioka, R. Ingemansson, S. Jeffery, C. Lee, S. Vig, N. Runkel, R. Martin, and J. Smith, "Evidence-based recommendations for negative pressure wound therapy: Treatment variables (pressure levels, wound filler and contact layer) - steps towards an international consensus," Journal of Plastic, Reconstructive \& Aesthetic Surgery, vol. 64, pp. S1-S16, sep 2011. [Online]. Available: https://doi.org/10.1016\%2Fj.bjps.2011.06.001 